\section{DE PREDICADORAS, HEROÍNAS Y MALENTENDIDOS}

\author{
Rocío Oviedo Pérez de Tudela \\ Universidad Complutense de Madrid \\ roviedopt@yahoo.es
}

Cómo citar este artículo/Citation: Oviedo Pérez De Tudela, R. (2016). "De predicadoras, heroínas y malentendidos". Arbor, 192 (778): a299. doi: http://dx.doi.org/10.3989/ arbor.2016.778n2002

Recibido: 08 septiembre 2015. Aceptado: 14 septiembre 2015.

RESUMEN: Algunas mujeres se adelantan a su tiempo, es el caso de la chilena María Luisa Bombal, o siglos atrás, de la monja mexicana sor Juana Inés de la Cruz, pionera en la defensa de los derechos de la mujer y su reconocimiento en la sociedad; pero también una adelantada al exigir su derecho a exponer opiniones propias en el complejo campo de la teología. Siglos después y desde parámetros muy distintos, Elena Poniatowska coincide con ella en reivindicar su independencia de reescritura y en el rescate de testimonios femeninos que son parte de la historia del México reciente.

PALABRAS CLAVE: Sor Juana Inés de la Cruz; Elena Poniatowska; Carta Atenagorica / Hasta no verte; Jesús mío. .

\section{PREACHERS, HEROINES AND MISUNDERSTANDINGS}

Copyright: (C) 2016 CSIC. Este es un artículo de acceso abierto distribuido bajo los términos de la licencia Creative Commons Attribution (CC BY) España 3.0.

ABSTRACT: Some women are ahead of their time. This is the case of Maria Luisa Bombal and the emergence of "real maravilloso", and also of Sor Juana Ines de la Cruz, a pioneer in the defense of women rights and their recognition in society, and before her time in demanding the right to express her opinions in the complex field of theology. Centuries later, Elena Poniatowska coincides with both of them in upholding her right to rewrite and rescue women's testimonies from the recent history of Mexico.

KEYWORDS: Sor Juana Inés de la Cruz; Elena Poniatowska; Carta Atenagorica / Hasta no verte; Jesús mío. 
La escritura es asexuada, pero los escritores mantienen su propia personalidad como hombres o mujeres. En el caso de María Luisa Bombal (1910-1980), ya en otra ocasión (Oviedo, 2003) destaqué tanto el papel que le correspondía como precursora de lo real maravilloso en un texto como "Las islas nuevas", como el carácter de una escritura femenina basada en dos aspectos: la preferencia por un tono melancólico con respecto al amor y el retrato del mundo del hogar.

El máximo ejemplo de la escritora consciente de su función como tal lo tenemos en Sor Juana Inés de la Cruz (1651-1695). Su actitud con respecto al feminismo es sobradamente conocida, especialmente por su defensa de los derechos de la mujer en su tiempo, algo palmario en la famosa redondilla "Hombres necios que acusáis". De igual modo, se pueden considerar otros escritos en los que la figura de la mujer aparece enaltecida más que por la belleza (frecuente en la poesía escrita por varones), por sus cualidades intelectuales o morales. Sin olvidar, que en su obra dramática Los empeños de una casa lo que destaca es la intriga femenina y presentar "en eficaz contraste a hombres y mujeres, los primeros violentos y hasta francamente tontos, las segundas vivas e inteligentes, hasta en sus enredos y en las soluciones que de repente adoptan para salvar su propia situación y dominar al otro sexo" (Bellini, 2009, p. 55). En un estudio reciente vuelve a destacar la reiterada opinión de sor Juana sobre la necedad de los hombres:

In ogni momento Sor Juana conferma l'orgoglio di essere donna e il disprezzo per gli uomini, sia che la critichino, sia che stoltamente la esaltino, in ognuno dei casi ritenuti “necios" (Bellini, 2014, p. 75).

Especialmente interesante en el caso de la literatura escrita por mujeres es el interrogarse por los motivos que originan su escritura. Respecto de sor Juana se han planteado todo tipo de teorías, pese a que contamos con la conocida Respuesta a sor Filotea, donde deja clara su voluntad e intereses. Obviamente, estas líneas no tienen como objetivo lo que ya se ha puesto de manifiesto una y otra vez. Pero aún quedan interrogantes sobre determinados aspectos biográficos, especialmente los dos que han ocupado más páginas de la crítica: el motivo que la llevó a la decisión de entrar muy joven en la vida conventual (apenas 16 años); y el abandono de lo que podría llamarse su "vida pública", que conllevó la decisión de vender su biblioteca y centrarse en sus tareas como religiosa. La solución al primer interrogante lo ofrece ella misma, y sin embargo se han multiplicado las opiniones sobre un desengaño amoroso. En cuanto al segundo punto, se suele insistir en la represión y dominio de la autoridad eclesiástica por encima de su voluntad. Es decir, en señalar la condición de sor Juana como mujer sometida, y sus posibles repercusiones en su literatura. Incluso obras cinematográficas de cierto éxito como Yo, la peor de todas, (Bemberg, 1990) se han hecho eco de las acusaciones. En mi opinión, y coincido con el Dr. Bellini entre otros críticos, los escritos de sor Juana en su tiempo nos hablan precisamente de lo contrario.

Sor Juana, quien en ningún momento deja de defender la condición de la mujer como tal y sus capacidades, es lo suficientemente inteligente como para convivir con la relativa armonía que, a todos los niveles, permite la sociedad de su tiempo. Su planteamiento ante los cometas, como se percibe al no salir en defensa de su amigo Sigüenza, avala una actitud que defienden, entre otros, Georgina Sabat de Rivers y José Antonio Rodríguez Garrido Este último, en su estudio del teatro de sor Juana, califica la fábula mitológica de Amor es más laberinto, así como el Neptuno, de speculum principis, es decir, la defensa de un paradigma vital (Rodríguez Garrido, 2002, p. 619).

El descubrimiento de la carta del obispo de Puebla por José Antonio Rodríguez Garrido (2004) ha traído de nuevo al marco de la realidad histórica la actitud de sor Juana y el reconocimiento y el aplauso de los eclesiásticos amigos que la rodeaban. Dos son los textos que el estudioso trae a la palestra, la Defensa del sermón del Mandato, firmado por el mexicano Pedro Muñoz de Castro el 9 enero de 1691; y el Discurso apologético en respuesta de la fe de erratas que sacó un soldado sobre la Carta Atenagorica (19 febrero 1691). La Defensa alaba a sor Juana, pero defiende al predicador. Como indica Rodríguez Garrido, el Discurso antecede en diez días a la famosa Respuesta a Sor Filotea de la monja mexicana. Al igual que La Defensa, es también feminista y partidario de que las mujeres enseñen, se burla del Soldado.

En la misma línea de afirmaciones en cuanto al reconocimiento de determinados clérigos y la negación de una prohibición por parte de Aguiar y Seijas se encuentra Benassy Berling, para quien "Sor Juana no se sentía víctima de persecución, sino más bien en posición de fuerza, lo que ya se desprende del texto. El arzobispo era de condición hosca, y algo misógino, pero acusarle de reducir al silencio a la Décima Musa en 1693 se funda en presunciones y carece de base concreta" (2006, p. 254). 
El único reproche del obispo de Puebla en su Carta de Sor Filotea se refiere al papel que a él mismo le corresponde como eclesiástico: dirigir a sor Juana hacia otras metas más elevadas: "lástima es que un tan gran entendimiento, de tal manera se abata a las rateras noticias de la tierra, no desee penetrar lo que pasa en el Cielo; y ya que se humille al suelo, que no baje más abajo, considerando lo que pasa en el infierno" (Sor Juana, 1952/1994b, p. 696). Conviene recordar que ella esgrimía con respecto a su propia vocación, no tanto una voluntad ascética, sino una ambición total por el conocimiento y su nula vocación al matrimonio (lo que también destaca su homóloga Santa Teresa). En su Respuesta... insiste en afirmar su deseo de saber y la necesidad de entregarse a él más que a ninguna otra actividad; sin olvidar que por entonces la teología se consideraba la cumbre de la sabiduría. Y sus escritos revelan que precisamente lo que más le interesa es la teología, como afirma en la Respuesta:

dirigiendo siempre [...] los pasos de mi estudio a la cumbre de la Sagrada Teología; pareciéndome preciso, para llegar a ella, subir por los escalones de las ciencias (Sor Juana, 1952/1994c, p. 447).

Así mismo, no es místico el único escrito que, según la propia autora, escribió con gusto, el Primer sueño, que también se puede considerar un excelente tratado de ascética; más aún si tenemos en cuenta toda la emblemática y la figuración del obelisco como el símbolo de la unión entre el cielo y la tierra con las pirámides invertidas de luz y sombra. Aún más, utiliza las vías de conocimiento más frecuentes como son el neoplatonismo y el aristotelismo que la identifican con una vertiente racionalista y no mística del conocimiento hacia la divinidad. Un racionalismo que coincide con la descripción de sus propios intereses y nos la muestra como una mente analítica y alertada siempre por la curiosidad.

Sin embargo esta actitud con respecto al conocimiento no disiente de una rebeldía con respecto a ciertas normas impuestas, como indican Veronica Grossi y Linda Egan:

Al final de la Respuesta el tono aparentemente apologético, las afirmaciones de inferioridad y de culpa de la narradora, conducen contrariamente a la orgullosa demostración de la superioridad intelectual y de la suprema capacidad literaria de la escritora. También en el Sueño la actividad profanadora, transgresora del sueño nocturno (...) termina por revelar el cuerpo triunfante del poema (Grossi, 1991, pp. 44-45).
Por no hablar de su consciente dimensión como poeta, y de su diferencia con respecto a sus coetáneos. Son constantes los avisos sobre la inconsistencia de las opiniones que vierten sobre ella: "La imagen de vuestra idea/ es la que habéis alabado; / y siendo vuestra, es bien digna / de vuestros mismos aplausos". Y termina con una ironía que contradice la mentalidad de su tiempo sobre la mujer, una sociedad que rechaza el hecho de que una mujer pueda destacar por su conocimiento: "Si no es que el sexo ha podido/o ha querido hacer, por raro/ que el lugar de lo perfecto / lo obtenga lo extraordinario" (Grossi, 2007).

\section{EL DERECHO DE LA MUJER A LA PREDICACIÓN}

Como se ha indicado previamente, sor Juana es plenamente consciente de su diferencia, su exclusividad dentro de los cánones de su tiempo, pero en todo caso, también de la mujer. Por este motivo, indicaba Enrico Mario Santi (1993), al descifrar las premisas de su tiempo se puede encontrar la respuesta a los interrogantes sobre la monja mexicana.

La insistencia en la singularidad de sor Juana por parte de sus coetáneos y de ella misma nos lleva a compararla con otros casos en los que la mujer ha adquirido un protagonismo especial, una diferencia que las destaca pese al machismo imperante en la época. Los casos más singulares los ostentan las abadesas. Desde el siglo XIII era frecuente su jurisdicción no solo en su propio convento, sino en aquellas tierras que les pertenecían: incluso, aparece documentado el uso de la mitra y el besamanos semejante al de los obispos. La propia sor Juana parece referirse a ello en su Respuesta al obispo de Puebla, al decir "que en la Iglesia primitiva se ponían las mujeres a enseñar las doctrinas unas a otras en los templos". Es más -continua"en el fervor de la primitiva Iglesia" las mujeres tenían el derecho de estudiar, incluso muchas a las que conocía el propio San Pablo. Así exige saber: "yo quisiera que estos intérpretes y expositores de San Pablo me explicaran cómo entienden aquel lugar: Mulieres in Ecclesia taceant" (Wade Labarge y Terán, 1988).

De acuerdo con estas afirmaciones, los casos de mayor interés para la erudita novohispana serían aquellos en los que la mujer ejercía cierta condición de cura de almas, es decir, en los que el pensamiento pudiera ser difundido a través de la predicación, pues no en vano su gran poema Primero Sueño es una alabanza a la filosofía y el conocimiento.

Cercano a su actitud y premisas, tanto por el nombre como por su actividad, es el caso de la llamada Santa 
Juana (1481-1534), que escogió también el apelativo "De la Cruz" cuando tras huir de un compromiso que no deseaba, se refugió en el beaterio de Santa María de la Cruz, en Numancia de la Sagra. Juana de la Cruz convirtió por orden divina el beaterio en monasterio de clarisas y su fama se extendió por la corte al recibir revelaciones de Cristo y convertirse en una especie de Catalina de Siena, cuyas palabras recogía al dictado una amanuense. Con ella iban a consultar varios miembros de la Corte, entre otros el duque de Alba, e incluso el mismo Carlos V. Cisneros extendió sus prerrogativas y fue nombrada predicadora y párroco para atraer a la fe con sus sermones a las almas sencillas. Un nombramiento que tras la muerte de Cisneros los superiores tratarán de evitar.

Cisneros además había apoyado a beatas y auspició la vocación de determinadas mujeres, como María de Santo Domingo, conocida por sus experiencias místicas y proclamaciones proféticas. Entre sus seguidores se incluyen al rey Fernando I de Aragón y el Duque de Alba (Zugasti, 2012, 33).

Por otra parte es relativamente fácil que la monja mexicana haya tenido noticias de esta santa homónima, que aún no lo era en su tiempo. La fama de esta mujer se difundió incluso a través de las representaciones dramáticas de la época, y así Tirso de Molina escribió tres piezas teatrales sobre distintos episodios de su vida. El público debía asistir con gusto a la representación de la obra, pues consta -como indica Zugasti (2012)- que al menos dos compañías la tuvieron en sus repertorios, Y lo que es aún más decisivo, se sabe que los reyes, en 1614, asistieron a la representación de la comedia "La santa Juana" como confirma en su relación Luis Cabrera de Córdoba. Es decir, no sería nada extraño que la propia duquesa de Mancera, tan amiga de la monja novohispana, hubiera asistido a alguna representación años después.

Incluso las relaciones de la época y los procesos en los que se ve involucrada la monja abadesa y predicadora se hacen eco de la profunda admiración de sus coetáneos:

Hablaba y predicaba como muerta, que predicaba con mucha teología y cosas de la Sagrada Escritura, y todos juntamente afirmaban el gran concurso de toda suerte de gentes que venían a oírla, que en particular había venido el emperador Carlos V, y el cardenal fray Francisco Jiménez de Cisneros, y el Gran Capitán y otras muchas personas, quedando todos muy maravillados de lo que oían (Triviño Monrabal, 1999, p. 99).
Por tanto, no nos puede extrañar si se tiene en cuenta la peculiaridad de sor Juana y los modelos en los que podía mirarse ella misma, que escribiera su Carta Atenagórica pensando en su edición. Así, esta escritura de sor Juana es signo de su libertad intelectual, especialmente por contradecir a un renombrado teólogo de la época, el Padre Vieira, en su discurso sobre las "Finezas de Cristo". En consecuencia y a tenor con las directrices de la época, considero que la publicación de la Carta Atenagórica, se debe no solo al deseo de dar a conocer el pensamiento de sor Juana por parte del obispo de Puebla; sino tal vez a otra finalidad: la defensa del derecho de la mujer a la predicación, a exponer un pensamiento teológico para su libre difusión. Obviamente, no era un tema fácil y sería sumamente extraño que el Obispo de Puebla lo defendiera, pero la dificultad no aminora el interrogante.

En apariencia, la teología era propiedad exclusiva de los hombres, como demuestra el hecho de nombramientos de doctores de la Iglesia desde el siglo XIII; mientras que habrá que esperar hasta bien cumplido el siglo XX para que se haga extensivo a las mujeres. Más aún, ni siquiera en el caso de la Santísima Virgen, los varones de la época se atrevían a reconocer la supremacía femenina, como demuestra el tardío reconocimiento del Dogma de la Inmaculada Concepción (8-XII-1854), pese a que ya en el siglo XV se había creado una orden bajo su advocación (las concepcionistas) por quien sería después Santa Beatriz de Silva, y así mismo la advocación es patrona de los franciscanos. De hecho, como confirma este desenlace de la Inmaculada, parecía impensable que ninguna mujer ni siquiera la Madre de Dios, se situara por encima de los hombres. Resulta incluso extraño que el propio Santo Tomás de Aquino no llegara a proclamarla, tal vez por su relación con las directrices de la llamada Escuela de la Sorbona, auspiciada por el pensamiento dominico frente a la escuela inglesa, cuyas premisas con respecto al inmaculismo erigió Duns Scoto. En este aspecto cabe destacar también la participación de Sor Juana en el concurso de Triunfo Parthénico, en honor de la Inmaculada, cuyo galardón ganó en los dos años consecutivos que describe Sigüenza y Góngora, su amigo, el insigne intelectual mexicano. Según Linda Egan, en la apreciación de sor Juana sobre la Virgen María se avizora un claro feminismo que llega a equiparar a la Virgen con el mismo Dios, divinizándola. Algo discutible al menos...

En todo caso sor Juana afirma el poder de la mujer desde un plano intelectual que abre el camino para su participación activa en la sociedad. Su voz es claramente femenina, pero en sus escritos de índole intelectual y no afectiva aflora una voz asexuada que busca dominar con el pensamiento. 


\section{DE LA COLONIA A LA REVOLUCIÓN: ELENA PONIATOWSKA}

\subsection{La independencia}

En la historia de México existe asimismo un caso singular de presencia de la mujer en la sociedad: las revolucionarias predecesoras de las soldaderas que también trataron de hacer escuchar su voz. En la literatura mexicana destaca una considerable cantidad de mujeres que desempeñan un papel decisivo en el proceso independentista. En ellas se cumple la imagen del héroe que destacara Joseph Campbell: frente al racionalismo anterior, de repente surge un pensamiento heroico en el que la mujer actúa y a quien se le puede aplicar los valores que definen al héroe: un ser que "ha sido capaz de combatir y triunfar sobre sus circunstancias históricas personales y locales" (1992, p. 26). El héroe es capaz de reunir en una unidad los elementos dispersos y darles sentido. Y estas mujeres son la suma de fuerzas de la Nación.

Las mujeres de la independencia de México se convierten en arquetipos que más adelante influyen en la revolución mexicana de 1910. Son -como dice Campbell- rito, mito o visión. Sin embargo, muy pocos escritores prestan atención a las mujeres que impulsan y animan la revolución de independencia. En Adictas a la insurgencia (2010), Celia del Palacio relata la sorpresa cuando al apresar a un capitán "el delicado capitán se despojó del bicornio adornado con plumas y galones para dejar en libertad una larga cabellera rubia y ondulada que cayó sobre sus hombros. Era una mujer". Se trataba de Maria Luisa Camba, llamada la Fernandina, cuya relación con $\mathrm{Hi}$ dalgo y la insurgencia corre en diferentes versiones. Su actuación es paralela a las que llevaron a cabo Bernarda Espinoza, encarcelada durante ocho años por ostentar su simpatía hacia los insurgentes; o Juana María Jiménez, condenada a dos años de prisión por ser sorprendida con municiones que planeaba entregar al bando de la independencia. Al igual que Susana Montero, Celia del Palacio destaca la escasa atención concedida a unas mujeres cuyo papel, según críticos e historiadores, se reducía a seguir a maridos o amantes por las trochas revolucionarias.

\subsection{La revolución}

Esta escasa valoración de las mujeres que pertenecieron a la insurgencia corre pareja a la de las soldaderas. Sin embargo, en este caso, una mujer, Elena Poniatowska alza su voz para reclamar el papel que la sociedad les ha negado. La distancia con respecto a sor Juana es de algo más de tres siglos, pero durante este tiempo la situación en México tampoco ha variado sustancialmente.

De hecho, como ya he indicado en otro momento, los escritores que forman parte de la larga nómina de novelas de la revolución mexicana prestan escasa atención a las mujeres; como si debiera ser otra mujer quien las retrate con mayor fidelidad. Me refiero a Edith O'Shaughnessy (1870-1939), periodista, guionista, biógrafa y mujer del encargado de negocios de la embajada norteamericana en México:

Podría escribirse un voluminoso libro sobre la conmovedora historia de la soldadera: la heroica mujer que acompaña al ejército, llevando consigo a sus hijos o cualquier otra posesión mortal [...]. Estas mujeres son el único avituallamiento visible de los soldados. Los acompañan en sus largas marchas; los cuidan, los alimentan, los curan y los entierran [...]. Es sorprendente la abnegación con que van por la vida. Y así siguen las pobres bestias hasta que mueren en el camino, para elevarse finalmente al cielo" (1916, p. 48).

Años después, las opiniones de Rosa E. King (18651955) son fruto de la propia experiencia; en su caso, enaltece aún más la figura de la soldadera y su actividad en la revolución:

Mis respetos para las mujeres mexicanas de esta clase [...]. Las mujeres que marchaban junto al soldado mexicano, que se adelantaban al lugar donde este acamparía para tener listo el refrigerio, que lo atendían en la enfermedad y lo confortaban cuando iba a morir, fueron asistentes e intérpretes, cumplieron su parte en la consolidación del actual gobierno liberal. iMujeres mexicanas educadas que apenas escapan de sus ciegos caparazones, recuerden esto y honren, donde quiera que ella se encuentre, a la soldadera mexicana! (1998, p. 139)

Poniatowska recoge el testigo de estos informantes y recrea mediante una escritura personal la figura de la soldadera. Se podría afirmar que desde sor Juana no hay ninguna otra mujer en México tan activa en el plano intelectual y desde la perspectiva de la escritura, como Poniatowska. Como Sor Juana, es una abanderada del feminismo, y coincide además en que su defensa se realiza por medio de la escritura, con la finalidad de conferir a la mujer un puesto esencial y decisivo en la sociedad de su tiempo.

Las entrevistas de Elena en buena medida están dedicadas a las mujeres que han destacado tanto por el papel artístico que desempeñan, como por su ca- 
rácter ejemplar en la sociedad. Por este motivo nos encontramos a Gabby Grimmer junto a Jesusa Palancares; pero también junto a Nahui Olin, Frida Kahlo, Remedios Varo, o Mariana Yampolsky.

Sin duda, el libro que saca a Poniatowska del anonimato, Hasta no verte Jesús mío (1969), consigue a su vez rescatar a una soldadera de ese mismo anonimato: Josefina Borquez, la Jesusa Palancares de su novela. Afincada y afianzada en el periodismo, Elena otorga una voz propia a su protagonista y lo hace desde la entrevista y el testimonio, siguiendo la estela que iniciara Barnet en la literatura hispanoamericana y que Poniatowska lleva a su punto más álgido. Mediante un estilo neorrealista presenta a Jesusa Palancares como una mujer y sobre todo, una soldadera en actitud de reto ante una sociedad que pretende silenciarlas. Frente a las conformistas y ficcionales heroínas de otras novelas, estas mujeres adoptan una actitud antisistema. La obra no analiza las teorías sobre el poder o la justicia de la historia que jalonan la narrativa de la Revolución mexicana, sino que surge del reportaje. La verdad de Jesusa, manipulada o no por la ficción, se funda en la experiencia pero también en la compleja personalidad de la antigua soldadera: apenas cuenta con dieciséis años en el momento de la revolución y la abandona al quedarse viuda, con dieciocho. Sus sentimientos personales respecto a su padre y marido son contradictorios y tan solo se descubren ante los muertos, como ocurre en el caso de su hermano. La muerte y la vida se igualan, ni la una ni la otra tienen valor para ella: ambas son cara de la misma moneda. Por este motivo llama la atención que su rebeldía, calificada por ella misma de "muy perra", se produce no ante la muerte, sino ante la injusticia, y sobre todo ante la consideración por parte del grupo social, de su banalidad como mujer. Su desprecio va dirigido hacia la mentira, la holgazanería y la injusticia. La decepción de los supuestos modelos, como ocurre con su padre, provoca un escepticismo que se viste de indiferencia, bajo cuya máscara se advierte con fuerza el sentimiento nunca manifestado.

Los mitos de Elena son los grandes perdedores, los grandes olvidados, las mujeres que se ponen en marcha, las que combaten sin fusiles, las que reclaman la verdadera fuerza de México, las que (desde el ninguneo que analizaba Paz) actúan y sirven y atienden con su voz, con su palabra, con sus ollas de arroz, con su sacrificio y su anonimato en Nada, nadie, las voces del temblor. Mujeres que pierden su identidad y se nos muestran como las grandes masas de soldados que pinta Siqueiros. Son esa parte pequeña e ignorada, que trata de abrirse paso entre las encrucijadas de los acon- tecimientos históricos. Y a través de la pluma de Elena las figuras destacan paulatinamente, apenas intangibles, se agigantan como las sombras hasta convertirse en el eje de la historia. Es necesario salvar su presencia, recuperar la imagen y la palabra de los olvidados. Recrear mediante la expresión oral un mundo de voces que sin el testimonio de la escritura hubieran sido silenciadas. Y en este aspecto aflora de nuevo la continuidad de una tradición, porque el testimonio junto a la literatura, es el vehículo que las artes plásticas adoptaron en los comienzos de la Revolución Mexicana. La ironía crítica de José Guadalupe Posada, que pervive en la obra de Rivera y Siqueiros, se abre paso como denuncia. Y la misma denuncia aflora años más tarde en la literatura de Poniatowska para hablar, no ya de un país maltratado, sino también del olvido de los sujetos más insistentemente castigados, entre ellos, la mujer.

La forma adoptada para realizar su narración procede de las mismas teorías que se establecieron en la Escuela de San Carlos, la escuela de Bellas Artes, 1) salir a la calle para pintar, de igual modo que Alvarez Bravo saca a sus alumnos a fotografiar cualquier rincón, cualquier sujeto o cualquier campo. Su literatura recoge la escena cotidiana pero oculta, y actúa a manera de cámara fotográfica que guarda una sorpresa. Los hechos contemplados en la calle, de cuña periodística, se insertan en el relato de ficción. El segundo método, 2) es la escritura fragmentada en la que se estructura el mundo que compone su narración. La suma de los fragmentos nos ofrece finalmente una perspectiva que se quiere simultánea y total del proceso. Estos dos parámetros, la realidad cotidiana y la fragmentación, son perceptibles incluso en las obras "históricas" como Querido Diego, te abraza Quiela. Por último, 3), la revelación de lo oculto o de lo ignorado. Mediante la intromisión en lo escondido, se revela la verdad: la banalidad de la revolución que no ha servido para mitigar los desequilibrios sociales.

Nada tan trágico como la expresión de la ausencia, con el lenguaje reducido, apenas capaz de manifestarse. Josefina Borquez, al igual que otras protagonistas de la obra de Elena, se caracteriza por el silencio -como advierte Rubén Rodríguez-; un silencio forzado, propio de la mujer en obras paradigmáticas de la literatura hispanoamericana como las de Rómulo Gallegos. Frente al silencio, Elena propicia la voz de sus protagonistas, extrayendo la palabra para que comuniquen; quiere romper el mutismo de la estatua -diría Rosario Castellanos-: “Antítesis de Pigmalión el hombre no aspira (...) a convertir una estatua en un ser vivo, sino un ser vivo en una estatua". 
Mediante la palabra y la denuncia, como se ha podido ver en los últimos sucesos de Ayotzinapa y en el discurso de recepción del doctorado Honoris Causa por la Universidad Complutense, Elena Poniatowska logra hacer evolucionar la posibilidad de la mujer para "predicar" en su propio tiempo. Desde el rescate de la soldadera a la denuncia logra, al igual que Sor Juana, exponer su pensamiento y recibir el aplauso de la sociedad. Porque ambas coinciden en la capacidad de hacer oír su voz... su voz de mujeres en los medios de comunicación que les son propios, los de la cultura de su tiempo. En suma, en ambas se percibe el orgullo de ser mujeres y el conocimiento de su valía, que las hace regresar seguras a su casa o a su celda. Por lo que a ambas se les puede aplicar las palabras con que Poniatowska retrata a Mariana Yampolsky:

y otra vez la emprende como una campesina fuerte, campanita de barro que regresa a la casa con su haz de trigo después de haber cumplido la tarea del día.

\section{BIBLIOGRAFÍA}

Bellini, G. (2009). Sátira y humor en sor Juana. En: Arellano, I. y Lorente, A. Poesía satírica y burlesca en la Hispanoamérica colonial. Madrid / Frankfurt: Iberoamericana / Vervuert, pp. 41-57.

Bellini, G. (2014). Gli hombres necios di Sor Juana. En: Serafin, S. (ed.) Ritratti di donne. Omaggio a Susana Regazzoni. Venezia: La Toletta Edizioni, pp. 67-75.

Benassy-Berling, M. C. (2006). [Reseña de La Carta Atenagórica de Sor Juana. Textos inéditos de una polémica, de J. A. Rodríguez Garrido]. Caravelle, 87, pp. 254-256.

Campbell, J. (1992). El héroe de las mil caras, psicoanálisis del mito. México: Fondo de Cultura Económica.

Castellanos, R. (1995). La mujer y su imagen. En Mejía, E. (ed.). Rosario Castellanos. Obras completas (vol. II: Poesía, teatro y ensayo). México: Fondo de Cultura Económica.

Cruz, Sor Juana Inés de la (1952/1994a). Carta Atenagorica. En Obras Completas. Mexico: Fondo de Cultura Económica (tomo IV), pp. 412-439.

Cruz, Sor Juana Inés de la (1952/1994b). Carta de Sor Filotea. En Obras Completas. Mexico: Fondo de Cultura Económica (tomo IV), pp. 694-698.

Cruz, Sor Juana Inés de la (1952/1994c). Respuesta a sor Filotea. En Obras Completas. Mexico: Fondo de Cultura Económica (tomo IV), pp. 440-474.

Dinan S. E. y Meyer, D. (2002). Mujeres y religión en el Viejo y el Nuevo Mundo, en la Edad Moderna. Madrid: Narcea.

Egan, L. Donde Dios todavía es mujer: sor Juana y la teología feminista [en línea]. Disponible en http://www. cervantesvirtual.com/obra-visor/don- de-dios-todava-es-mujer---sor-juana-yla-teologa-feminista-0/html/1adc24b9f972-47ac-b33b-b74285fd1942_4.html

Grossi, V. (1991). El triunfo del poder femenino desde el margen de un poema: Otra lectura del Primero Sueño de Sor Juana Inés de la Cruz. Mester, 20, 2, pp: 27-40.

Grossi, V. (2007). Sigilosos vuelos epistemológicos en Sor Juana Inés de la Cruz. Madrid / Frankfurt: Iberoamericana / Vervuert.

King, E. (1998). Tempestad sobre México. México: Conaculta.

Lorite Ruiz, P. J. (2014). La iconografía de las abadesas mitradas, mujeres que prácticamente fueron obispos. En Cabrera Espinosa, M. y López Cordero, J. A. (dirs.). VI Congreso virtual sobre Historia de las Mujeres, pp. 337-351. Disponible en file:///C:/Users/user/Downloads/Dialnet-LalconografiaDeLasAbadesasMitradasMujeresQuePracti-4947247.pdf

O'Shaughnessy, E. (1916). A Diplomat's Wife in Mexico. Letters from the American Embassy at Mexico City, covering the dramatic period between October 8th, 1913, and the breaking off of diplomatic relations on April 23rd, 1914, together with an account of the occupation of Vera Cruz. New York: Harper and Brothers Publisher.

Oviedo, M. R. (2003). Huellas en camino. Narrativa de mujeres en Chile. Quaderni Ibero-Americani. Homenaje a Chile, 92, pp. 71-88.

Oviedo, M. R. Revolucionarias y soldaderas (en línea). Disponible en http://cvc.cervantes.es/literatura/mujer_independencias/oviedo.htm

Oviedo, M. R. (2011). Mujeres de la revolución mexicana / mujeres ante la revolución mexicana. En: Lorente, A. y Navascués, J. de (eds.). Narrativa de la Revolución Mexicana: realidad histórica y ficción. Madrid: Verbum, pp.147-165.

Palacio, C. del (2010). Adictas a la insurgencia. México: Punto de Lectura.

Poniatowska, E. (1988). Hasta no verte, Jesús mío. Madrid: Alianza.

Poniatowska, E. (1999). Las soldaderas. México: Era-Conaculta

Poniatowska, E. (2001). Mariana Yamnpolsky y la bugambilia. Barcelona: Plaza \& Janés.

Rodríguez Garrido, J. A. (2002). Escritura femenina y representación del poder en Amor es más laberinto de Sor Juana Inés de la Cruz (Loa y comedia). En: Ballón Aguirre, E. y Rivera Rodas, O. (eds.). De palabras, imágenes y símbolos: homenaje a José Pascual Buxó. México: Universidad Nacional Autónoma de México, pp. 615-634.

Rodríguez Garrido, J. A. (2004). La Carta Atenagórica de sor Juana. Textos inéditos de una polémica. México, Universidad Nacional Autónoma de México. Facsímil en formato electrónico.

Triviño Monrabal, M. V. (1999). Mujer, Predicadora y Párroco. La Santa Juana (1481-1534). Madrid: BAC.

Wade Labarge, M. y Terán, N. de (1988). La mujer en la Edad Media. San Sebastián: Nerea.

Zugasti, M. (2012). Compañías, autores y actores en torno al estreno de la trilogía de La santa Juana (1613-1614), de Tirso de Molina. Teatro de palabras. Revista sobre teatro áureo, 6, pp. 31-81. 